\title{
Models of Education: In-Depth Review
}

\author{
S. F. Sagimin ${ }^{1}$ and M. N. Abdulwahab ${ }^{2}$ \\ Centre for Modern Languages \& Human Sciences, Universiti Malaysia Pahang \\ ct.fatimah@gmail.com,nubli@ump.my
}

\begin{abstract}
The information in this review provides comparative assessments of major educational models currently being used worldwide. The purpose of this literature review is to develop a frame of reference for both models of education and that of teacher selfefficiency using relevant research studies to illuminate the possible relationship between these two variables. To serve its purpose, this paper will cover some types of educational models and will be designated as part 1. Part 2 will thus be covered in future manuscript. In short, this article focuses on two variables-education techniques or models and their implementer, i.e. the teacher.
\end{abstract}

Keywords: Education, Models, Assessment, Teachers

\section{Introduction}

Over many decades the processes of learning and teaching have changed significantly to adapt to human needs and fulfill the requirements of evolving societies. Two common elements associated to any learning and teaching methods are students and teachers. The two of them are reflections of one another's success in their professions. As a teacher, successful students indicate healthy teaching process, while successful teachers imply well-established learning styles.

This paper gives in-depth review of popular learning methodologies up to date. It covers mastery, outcome-based, competency-based, and school-based learning educations. It shows the pros and cons of each education model and highlights major points related to that type of education

\section{Mastery Learning Education}

Mastery learning is a theory as well as a teaching strategy. As a set of instructional practices, it helps most students to learn at high levels. As a theory, it postulates that all students if given the time can master the coursework. It is based on the belief that all students can learn [1-2]. The work of Carroll [3] was influential in the development of mastery learning in arguing that students have different needs in the amount of time to learn a given unit of study. In addition to the quality of instruction and the ability to understand the instruction, [4] argues, the student's aptitude for the subject determines the time needed for each student to master the learning.

Bloom [9] developed the Learning for Mastery (LFM) model in which students receive individualized instruction to master all course material.

The LFM model states:

1. The learner knows what must be mastered and how;

2. The order and formulation of instructional objectives is important;

3. The course is broken into smaller units with corresponding tests;

4. The teacher provides feedback and correction after each test; 
5. The teacher provides the time students need to learn;

6. Alternative learning opportunities should be provided; and

7. Students work in small groups to review test results and help each other understand errors [9].

Another influential model is Keller's [15] Personalized System of Instruction (PSI) that is defined by four characteristics:

1. Students move at their own pace;

2. Students move from one unit to the next after they demonstrate mastery;

3. Lecture is minimized as a teaching strategy. Students are given objectives, reading material, and study questions to prepare for tests; and

4. Instructional staff resources are used to help students correct errors.

Both LFM and PSI assume that all students can master what they learn in school [5-6]. In addition to identifying explicitly the course objectives to master, breaking down the course into smaller units of study, teaching each unit to mastery, and assessing after each unit and at the end of the course, both LFM and PSI are designed to be used in a traditional classroom setting [6-8]. Since both models can be used in a traditional classroom, the format can be implemented whole-class and teacher led, or on an individual basis that is self-paced [9-10]. Guskey [23] pointed to two key elements of mastery learning, "feedback and correctives, and congruence among instructional components". Students are provided with timely, constructive feedback that is appropriate for their level as well as praise for their accomplishments. In addition, students must be given specific directions on how to correct any errors in a way that differs from the initial teaching. Students must be provided with alternate pathways to reach mastery. By doing so, mastery learning provides a more individualized form of instruction. Mastery learning does not prescribe what should be taught, or how it should be taught, but it does require that the curriculum, instruction, and assessment be directly aligned with student outcomes [23]. The research on mastery learning has resulted in conflicting results on its effect on student achievement [16-20]. Critics of mastery learning contend that there is little research on achievement in studies other than basic skills [16]. In areas such as reading and writing, content cannot be easily divided into smaller units in a systematic way that can be assessed logically [21] argued that there is a discrepancy between theory and practice. However, even proponents of mastery learning concede that additional classroom time is needed for the learning process [9]. [6], in a review of the research on mastery learning, noted that mastery-learning strategies do increase student learning as opposed to non-mastery approaches. Furthermore, the positive effects of mastery learning on slower students are [20-24]. Bloom [9] identified two unforeseen outcomes of mastery learning; the development of cooperation rather than competition and an increase in student self-efficiency. Research studies suggested that the amount of time alone does not predict achievement; the quality of instruction is also an important factor [7]. Guskey [10] conducted a meta-analysis to study results of group-based mastery learning. The analysis was narrowed down to 27 methodologically sound studies in which students progress through instructional sequence as a group and was teacher-paced in an elementary or secondary classroom. The studies focused on five areas: student achievement, student learning retention, time variables, student affect, and teacher variables. The effect size was used to evaluate the outcomes of each study and the overall effect of mastery learning [11]. In the area of student achievement, the results showed larger effect sizes in elementary classrooms than secondary classrooms as well as larger effect sizes in social studies and language arts than math and science. The results of the studies that investigated student retention found that group-based mastery learning had a positive 
effect on student learning retention. Evidence, from studies that investigated time variables, suggested that the differences between fast and slow learners decrease under mastery learning. In terms of student affect, results showed mastery learning has a positive effect on students' attitude toward the subject they are studying. In the area of teacher variables, mastery learning was shown to have a positive effect on teacher attitudes, expectations, practices, and behaviors [12]. Although the preponderance of the research provides evidence of the positive effects of mastery learning on student learning, the increase of time needed for students and teachers has not been adequately studied for its effectiveness and efficiency [12-14]. Martinez [15] expanded on previous research by studying the main effects for mastery learning in 2 mastery and 2 traditional algebra classes with a total of 80 students. The teacher used a group-based approach to instruction in both the experimental and control groups. The randomized factorial design found that learning outcomes for both groups did not differ significantly, however there was a dramatic difference in the instructional time. The mastery groups required twice as much instructional time [15].

\section{Outcomes-based Education}

Outcomes-based education (OBE), outcomes-based learning (OBL), outcomes-based learning and teaching (OBLT), or the outcomes driven developmental model (ODDM) are all similar concepts and are based on a constructivist philosophy of education with a wide variation in their implementation. In simplest terms, OBE is a student output-based system in which student need is based on output performance; setting outcome expectations for students to achieve, ensuring through teaching and re-teaching in as many different ways as possible for as long as it takes until everyone meets them [12]. OBE is centered not so much on what is taught, but on what is learned [17]. OBTL runs on a capacity building model where the quality of teaching is judged by the quality of learning [17]. Once outcomes are identified, all educational practices should be aligned with these outcomes [18]. When implementing a newly devised OBTL system, the entire curriculum is redesigned; teachers plan curriculum by creating a set of Independent Learning Outcomes (ILO) from which they identify a set of Teaching and Learning Activities (TLA's) that students can creatively and actively participate in to construct meaning and knowledge which align with the ILOs [17]). Transitional forms of OBE, such as ODDM, identify outcomes, but postpone redesigning the entire curriculum [18]. "Outcomes" under OBTL do not necessarily constitute a physical "output", but rather things that happen to the students, and/or the teachers or even the institution. Practitioners of OBE determine what students should be able to demonstrate when they finish school labeled "exit outcomes" and the curriculum and instructional strategies are aligned to enable all students to achieve these outcomes or goals [19]. Transformational OBE is not focused on curriculum outcomes within individual subject areas, but the performance capabilities of students and their ability to perform complex tasks relating more directly to real life situations [20]. In transformational OBE, learning is no longer based on years and set periods of time for completion [20]. OBE literature is mainly made up of anecdotal success stories, perceptual studies, and promotion pieces [21]. The reason for this seems to be due to the fact that, OBE is an umbrella concept under which various reform efforts can be placed. Thus, OBE is difficult to operationalize into a single definition due to the fact that it is an overall approach to school improvement in which many tangential models abound [22]. Relevant research can be found in [20]. Evidence drawn from mastery learning, which many believe is an integral part of OBE, provides some relevant research to the literature. Kulik et al., [6], in a comprehensive meta-analysis of 108 studies, examined mastery learning and Keller's Personalized System of Instruction (PSI), both of which present material in short units and provide formative tests. The findings indicated that the average student in a mastery learning class performed in the 70th percentile 
whereas the average student in a control class performed in the 50th percentile. In a study, covering a period of three years (2006-2009), 18 workshops were conducted in Hong Kong pertaining to teaching creativity and learning using an OBTL model [17]. Roughly 110 adults ages 30 and above, 140 secondary to first-year university students ages 16-20, and 60 children ages 6-12 participated [4]. Both observational and portfolio assessment data were used as a means for analysis. This study concluded that in-depth analysis and understanding of TLAs with a project design is crucial when implementing OBTL as a basis of teaching and learning creativity [17]. If OBTL is devised with rigid guidelines, students produce insufficient creativity in executing the constructive alignment and designing of the outcomes; therefore, a loose form of OBE is suggested to improve creativity [17]. Donnely [6] summarized the affect OBE had on the entire educational system in Australia, South Africa, and the United States during the 1990s. Some of the criticisms and concerns addressed are summarized as follows:

- An excessive number of curriculum outcomes required, especially in the primary grades;

- Superficial, vague, and overly generalized outcome statements that work against the acquisition of essential knowledge, understanding, and essential skills associated with subject disciplines;

- Management of individual student assessment data is overly time consuming, difficult, and unfairly increases the workload of teachers;

-Weakening of the idea of striving for success for students by eliminating the concept of failure;

- Overemphasis on criterion referenced assessment to the detriment of norm referenced assessment;

- Emphasis on subject knowledge is reduced in preference to skills and processes; and

- Heavy demands placed on teachers to create curriculum.

Much of Donnely's [17] criticism was based on the failed implementation of OBE in South Africa, Australia, and the United States in which OBE was replaced with a standards-based model. In Australia, OBE was criticized by parents and teachers and was mostly dropped in 2007. OBE was dropped in South Africa in 2010. OBE was a popular term in the United States during the 1980s and 1990s, but was modified and called mastery learning and standards-based education among other terms. Ultimately, the No Child Left Behind Act came into prevalence in the 1990s in which the standards-based movement prevailed. While the standards-based movement has elements of OBE, the traditional style of education in which the standards-based system is housed delineates it starkly from OBE.

\section{Competency-based Education}

Competency-based education, a system of education that has emerged and re-emerged at various times, was originally a product of the 1970s [11]. Competency-based education is commonly defined as an educational model in which there is a clear, measurable definition of mastery, along with procedures and tools for tracking that mastery. Students progress at their own pace, based on what they can show that they know [13]. [14] added that competency-based education "is not predicated on seat time, but upon observable activities demonstrated by the learner. Under this new guise, a diploma is not guaranteed by growing older and staying out of trouble". Historically, competency-based principles are rooted in vocational education [13-16], and often appear in earlier works specific to vocations like psychiatric care, clinical education, therapy, and teacher education 
programs [12]. Competency-based refers to an instructional system where students are given credit for performing to a predetermined level of proficiency under specified conditions [9] because of fears that teaching facts and techniques provided students with information that quickly became obsolete [3]. Barris [3] stated that competency-based education brings together similarly successful elements of theoretical educational frameworks, like Dewey's model of problem solving and Rossman's model of creative invention. Dewey's model of problem solving involves 1. A felt difficulty; 2. Location and definition of the difficulty; 3. Generation of possible solutions; 4. Consideration of their consequences; and 5. Acceptance of a solution [7]. Rossman's model of creative invention includes, 1 . An observed need or difficulty; 2. Formulation of a problem; 3. Survey of available information; 4. Formulation of solutions; 5. Critical examination of solutions; 6. New ideas; and 7. Testing and acceptance of new ideas [7]. Barris [6] added that competency-based education is essentially education revolving around problem solving, and uses limited available literature at the time to confirm that, at the very least, it provides a new perspective for processes and outcomes. [5] outlined six essential elements to a competency-based education: outcomes, time, instruction, measurement, certification, and program adaptability. A student can reach the desired competencies via a variety of pathways and these competencies can be met in a flexible timeframe [3-6] concurred that competency-based education program time is not fixed. Scheduling is flexible and opportunities are provided to help students become ready to acquire competencies [17]. Learning units or targets are designed in order for students to gain mastery [18]. Alternate paths are provided to accommodate diverse learning styles. In addition, the system is built on a shared mission that is developed with all stakeholders and is continuously monitored and revised [18]. Another characteristic of a competencybased system is the development of curriculum and design of instruction that are continuously reevaluated and adjusted to address the needs of diverse student populations [17]. Curriculum is often customized to meet the needs of students as well as teachers. Assessments are aligned with competencies and are taken when the student is ready to demonstrate mastery [11]. Although students achieve mastery once they can demonstrate proficiency or competence, they must do so as a product of their own responsibility [16]. As [15] articulated, "the teacher is, indeed, a primary participant in the selection and implementation of goals, but he is not the most important member of the learning team". [13] warned that until the partnership between teachers and students is formed in this manner, competency-based education will only be an educational fad. [22] explored competency-based education by reflecting on the negative and positive aspects. Advantages are that of flexibility, scheduling, and higher standards, while disadvantages are the expense, questions of reliability and validity, and having to answer, "how much of the skill students must demonstrate to be termed "competent" [22]. [23] cited the same advantages, as well as identifying assessment specificity, but adds further weakness in the form of technology needs. [23] called for research relating competency to the real world - and particularly technology use in the real world.

\section{School-based Education}

The terms school-based and competency-based have been used to describe the next generation learning that challenges the traditional mode of education [2]. School-based learning customizes education to prepare students for college and career. [3] argued, "learning objectives within specific content domains must be discarded in line of objectives that reflect more realistic life roles". [7] offered the following working definition of a school-based approach:

- Students advance upon mastery; 
- Competencies include explicit, measurable, transferable learning objectives that empower students;

- Assessment is meaningful and a positive learning experience for students;

- Students receive timely, differentiated support based on their individual learning needs; and

- Learning outcomes emphasize competencies that include application and creating of knowledge, along with the development of important skills and dispositions.

A current discussion regarding school -based education found in a report written by [8] described a new working definition of competency-based education. Students in a competency-based system proceed along a continuum based on mastery. The learning objectives are explicit, measureable, and applicable. The assessments are meaningful and provide a positive learning experience. Evidence of student learning is an essential component of a SBA [8]. In addition, students are provided differentiated instruction that is based on their specific needs. [9] pointed out that competency-based designers emphasize two sets of competencies:

One develops creativity, problem solving, and communication, while the other develops personal skills such as perseverance, cultural competency, and study skills. Both of these competencies prepare students for college and career [23].

The SBA is aligned with the demands of the global economy [20]. The major difference between competency-based education that was produced in the 1970s and contemporary models of school-based systems of education (modern competency-based education) is the shift away from mostly vocational pathways toward college and career pathways and a strong reliance on technology [24].

\section{Conclusions}

This work has shown the possible correlation between major educational models currently in use and the so-called teacher efficacy. Several models of education have been explained in thorough details along with corresponding literature to highlight the link between the two variables mentioned earlier. The study pinpoints the road map to further studies to explore this relationship.

\section{References}

[1] K. Ash, "Competency-based schools embrace digital learning", Education Week: Digital Directions, 6(1), 36-41. Retrieved from http://www.edweek.org/dd/articles/2012/10/17/01S\&cmp=ENLEUNEWS1\& intc=es, (2012).

[2] P. Ashton, "Teacher efficacy: A motivational paradigm for effective teacher education", Journal of Teacher Education, vol. 35, no. 5, (1984), pp. 28-32.

[3] P. Ashton and R. Webb, "Making a difference: Teachers' sense of efficacy and student achievement", New York, NY: Longman, (1986).

[4] A. Bandura, "Social learning theory", Englewood Cliffs, NJ: Prentice Hall, (1977).

[5] A. Bandura, "Perceived self-efficacy in cognitive development and functioning", Educational Psychologist, vol. 28, no. 2, (1993), pp. 117-148.

[6] A. Bandura, "Self-efficacy", In V. S. Ramachaudran (Ed.), Encyclopedia of human behavior, New York, NY: Academic Press, vol. 4, (1994), pp. 71-81.

[7] J. H. Block, "Promoting excellence through mastery learning", Theory into Practice, vol. 19, no. 1, (1980), pp. 66-73.

[8] J. H. Block and R. B. Burns, "Mastery learning", Review of Research in Education, vol. 4, (1976), pp. 3-49.

[9] B. Bloom, "Recent developments in mastery learning", Educational Psychologist, vol. 10, no. 2, (1973), pp. 53-57.

[10] B. Bloom, "Human characteristics and school learning", New York, NY: McGraw-Hill, (1976).

[11] B. Bloom, "New views of the learner: Implications for instruction and curriculum", Educational Leadership, vol. 35, (1978), pp. 563-576.

[12] J. B. Carrroll, “A model of school learning”, Teachers College Record, vol. 64, (1963), pp. 723-733. 
[13] R. J. Collie, J. D. Shapka and N. E. Perry, "School climate and social emotional learning: Predicting teacher stress, job satisfaction, and teaching efficacy", Journal of Educational Psychology, vol. 104, no. 4, (2012), pp. 1189-1204.

[14] C. Day, A. Kington, G. Stobart and P. Sammons, "The personal and professional selves of teachers: stable and unstable identities", British Educational Research Journal, vol. 32, no. 4, (2006), pp. 601-616.

[15] E. Deci, R. Vallerand, L. Pelletier and R. Ryan, "Motivation and education: The self-determination perspective", Educational Psychologist, vol. 26, no. 3 \&4, (1991), pp. 325-346.

[16] J. DeCoster, "Overview of Factor Analysis", Retrieved from http://www.stathelp.com/notes.html. (1998).

[17] R. Delorenzo, W. Battino, R. Schreiber and B. Gaddy Carrio, "Delivering on the promise", Bloomington, IN: Solution Tree, (2009).

[18] B. Fuller and J. Izu, "Explaining school cohesion: What shapes the organizational beliefs of teachers", American Journal of Education, vol. 94, (1986), pp. 501- 535.

[19] C. H. Geer and J. Q. Morrison, "The impact of the collective efficacy of a school community on individual professional development outcomes", MidWestern Educational Researcher, vol. 21, no. 4, (2008), pp. 32-38.

[20] G. Ghaith and H. Yaghi, "Relationships among experience, teacher efficacy, and attitudes toward the implementation of instructional innovation", Teaching and Teacher Education, vol. 13, no. 4, (1997), pp. 451-458.

[21] R. Goddard, W. Woolfolk- Hoy and A. Hoy, "Collective teacher efficacy: Its meaning, measure, and impact on student achievement”, American Educational Research Journal, vol. 37, no. 479, (2000), pp. 1-30.

[22] J. A. Grissom, "Can good principals keep teachers in disadvantaged schools? Linking principal effectiveness to teacher satisfaction and turnover in hard-to-staff environments", Teachers College Record, vol. 113, no. 11, (2011), pp. 2552- 2585.

[23] T. R., Guskey, "The essential elements of mastery learning”, Journal of Classroom Interaction, vol. 22, no. 2, (1987), pp. 19-22.

[24] D. Hanna, "Designing organizations for high performance", New York, NY: Addison-Wesley, (1988).

[25] E. Hinde, "Reflections on reform: A former teacher's look at school change and the factors that shape it", Teachers College Record, (2009). 
International Journal of Education and Learning Vol.4, No.2 (2015) 